\title{
STUDY ON BEHAVIOR OF STEEL OUTRIGGER WITH VERTICAL IRREGULARITY AGAINST LATERAL LOADING
}

\author{
Spoorthi D C $\mathbf{C}^{\mathbf{1}}$, Sridhar $\mathbf{R}^{\mathbf{2}}$ \\ ${ }^{1}$ Student, Department of Civil Engineering, NCET, Karnataka, India \\ ${ }^{2}$ Sr.Associate Professor, Department of Civil Engineering, NCET, Karnataka, India
}

\begin{abstract}
The outrigger system has become the one of the most efficient lateral load resisting system in modern tall buildings. By providing the outrigger, the stiffness of the building increases, so that which increases the performance of building under the lateral loads. In the present comparative study the static and dynamic behavior of the reinforced concrete structure for different cases in regular and vertical irregular building $9 \times 9$ bays 40 storey $3 D$ RC structure is modeled in SAP2000 software program. In this comparative study mainly the bare frame is compared with Steel outrigger with core for both regular and irregular building for zone 5 and wind speed $55 \mathrm{~m} / \mathrm{s}$. Efficiency of the structure measured in terms of lateral displacement, drift, Base shear and time period for different cases of models. Parameter should be in such a way that it should prevent the structural and non-structural damages to the building.
\end{abstract}

Keywords: Tall Building, Regular and Irregular Building, Lateral displacement, Lateral dirft, Base shear and Time Period

\section{INTRODUCTION}

Mankind has always possessed for height throughout our history, he always thought of reaching for the stars. From old era to today's new technological era, capacity and success of a civilization or country are consistently executed on magnificent buildings. There will be incredible opportunities for the building professionals as the structure height increases in the construction field.

Advanced different architectural and structural forms are improved by the finite element approach which implements the development of structural and design software. This made very easy to analyze the structure in accurate way. The fundamental aspect which change the manner of designing the structure are the analyzing the behavior of structure and influence on computing tools.

Lateral load imposed on the structure is the important factor in the study of Tall building. Structural Engineer has been facing challenges to access the imposed drift requirements and minimizing the architectural strength of the structure as the building have got taller and taller. In response to this above concept, a large number of lateral resisting schemes are introduced for the tall buildings.

\subsection{Effect of Vertical Irregularities}

Failure of structure is originates from the weakest points during the Earthquake. The structural discontinuity present in the structure is termed as Irregular structures. Based on the location of discontinuity in the building, the structural irregularity is mainly classified into two types that are, Plan Irregularity and Vertical Irregularity. Among these two irregularities, Vertical irregularities are having the greater effect during the earthquake results in failure of structure.

Distribution of stiffness, mass and strength is considered either separately or in combination for the effect of vertical irregularities on the seismic behavior. A base case structure, which represent the irregular structure is developed and are defined by modifying the vertical distribution of mass, stiffness or strength of the base case.

The seismic response of the building structures is more sensitive to stiffness irregularities than to mass irregularities of similar magnitude. Even small changes in storey shear strengths may lead to a significant change in seismic demands. Effect of irregularity depended on extent and location of irregularity and variations in seismic response parameters was found at the vicinity of irregularity.

\subsection{Outriggers}

From past four decades, Outrigger has been used in the construction industry but it has significance as a structural member from long ago. Sailing ship industry have been used the outrigger from a long back in order to resists wind effect on ships. Outriggers are provided with regard of slender mast. As a resemblance, slender mast is act as core, outriggers are emerging out from the mast like spreaders and exterior columns represent the shrouds or stays.

The Structural Design of tall structures should be in such a manner that it should give least lateral drift by using minimum steel tonnage which in turn reduces the cost. In this regard numerous bracing techniques have been introduced in the construction field. Among them outrigger 
system is the most efficient which increases the stiffness of the building which in turn increases the resistance towards overturning ability of the building.

The structure which consist of either shear wall or steel bracing truss as a core and horizontal trusses as outriggers are the most efficient form of structures. Lateral deflection and moment in the core are caused due to the horizontal loading on building which resisted by the rotation created by the restrained column should be less than the lateral deflection and moments induced in the free standing core. By inducing tension in the Windward columns and compression in the leeward column it the building acts as a vertical cantilever beam and by increasing the depth of the structure, more efficient results can be obtained.

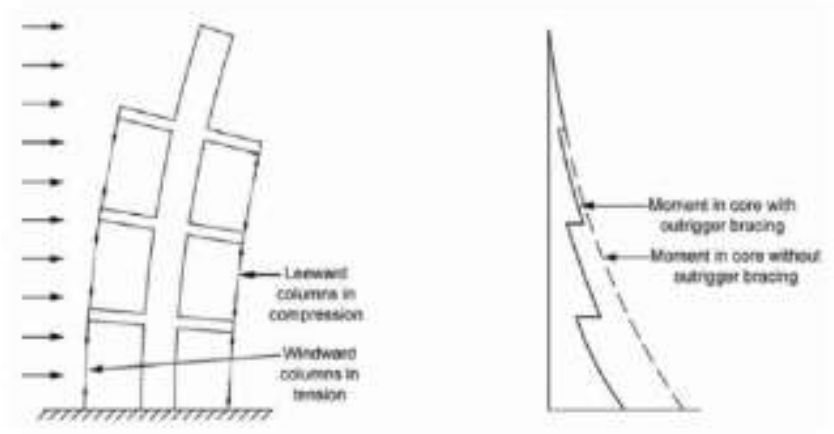

Fig.1. Interaction of Core and Outrigger

\subsection{Aim and Scope of Study}

$>$ The objective of present study is the use of outrigger in regular and vertical irregular building under earthquake forces as well as wind loads.

$>$ Reinforced 40 storey framed structure is considered in this study.

$>$ Both regular steel building and irregular steel building is considered for this comparative study.

$>$ Parameters kept constant in analytical study are height and Outrigger location for the different cases of building.

$>$ The buildings with and without outrigger are compared.

$>$ The outriggers are introduced at two levels in the building.

$>$ The results of different parameters such as displacement, drift, Base shear and time period are studied.

$>$ The reduction in drift, deflections and fundamental time period of the regular and irregular building are studied.

\section{MODEL DESCRIPTION}

Structure - OMRF

Number of stories- 40

Type - Regular and Vertical Irregular Building

Storey Height $-3 \mathrm{~m}$

Grade of Concrete - M30

Grade of steel $\quad-\mathrm{Fe} 415$

Beam Size $\quad-0.3 \times 0.6 \mathrm{~m}$

Column size $\quad-0.6 \times 0.6 \mathrm{~m}$

Slab size $\quad-0.15 \mathrm{~m}$ thick
Seismic Zone

Wind speed $\left(\mathrm{V}_{\mathrm{b}}\right)$

Soil type

Importance Factor

Reduction Factor

Live Load

SDL

Core

Outrigger

All columns are assumed to be fixed at their base

Regular building model is having symmetrical plan with plan dimension $40 \times 40 \mathrm{~m}$ where as the vertical irregularity building model is having plan dimension of $30 \times 30 \mathrm{~m}$ up to 8 th storey, $30 \times 35 \mathrm{~m}$ plan from 9 th to16th and 25 th to $32 \mathrm{nd}$ storey, $35 \times 30 \mathrm{~m}$ plan from 17 th to 24 th and 32 nd to 40 th storey. Plan is having 20x20 central core opening with outriggers and without having outriggers. The three dimensional model is carried out for the analysis. The columns and beams are of frame type elements whereas slabs and shear walls are of shell type element. The proposed structure is subjected to four types of load patterns according to the Indian standards. The four types of loads are Dead load, live load, seismic load and wind load.

\section{RESULTS AND DISCUSSION}

Results obtained by each models are discussed in this chapter. The analysis carried out by equivalent static and response spectrum method. The parameters discussed in this study include displacement, drift, base shear and time period. Parameters of different models of regular building are compared with the parameters of different models of irregular building. In addition to this all models are evaluated with different types of zones and different wind speeds are also discussed.

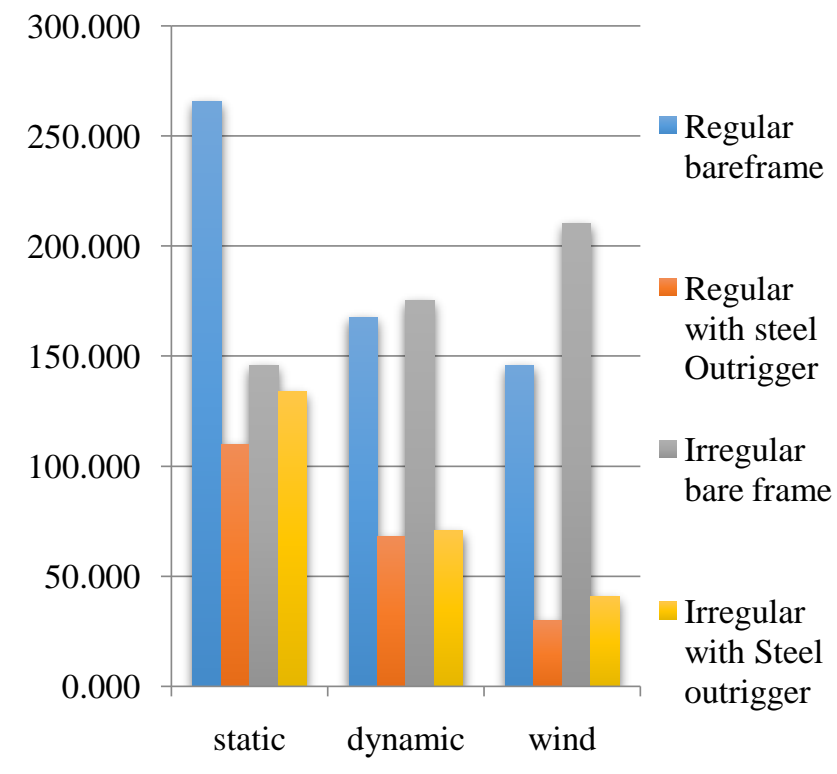

Chart -1: Maximum Lateral Displacement for Zone 5 and Wind speed $55 \mathrm{~m} / \mathrm{s}$ 
Above graph shows the maximum displacement of regular and irregular structure with and without Steel outrigger for static and dynamic analysis in zone5 and wind analysis at wind speed $55 \mathrm{~m} / \mathrm{s}$. From the graph it is observed that the maximum displacement of bare frame gives highest and structure with Steel outrigger gives lowest values in all the three analysis. The percentage of reduction in the values found to be $59.5 \%$ and $59.74 \%$ for regular and irregular building with steel outrigger from bare frames for dynamic analysis.

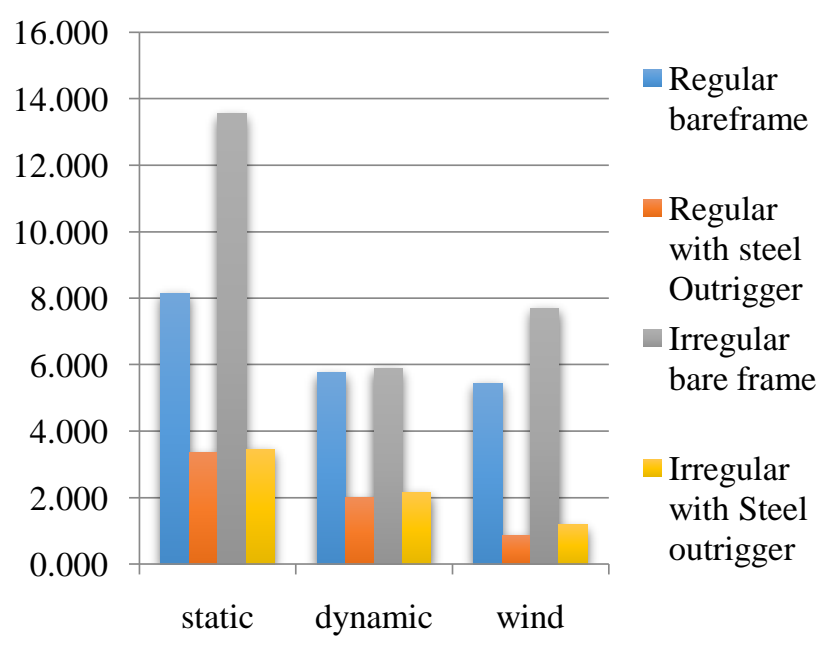

Chart -2: Maximum lateral drift for Zone5 and wind speed $55 \mathrm{~m} / \mathrm{s}$

Above graph shows the maximum drift of regular and irregular structure with and without Steel outrigger for static and dynamic analysis in zone 5 and wind analysis at wind speed $55 \mathrm{~m} / \mathrm{s}$. From the graph it is observed that the maximum displacement of bare frame gives highest and structure with steel outrigger gives lowest values in all the three analysis. The percentage of reduction in the values found to be $65.34 \%$ and $63.6 \%$ for regular and irregular building with steel outrigger from bare frames for dynamic analysis.

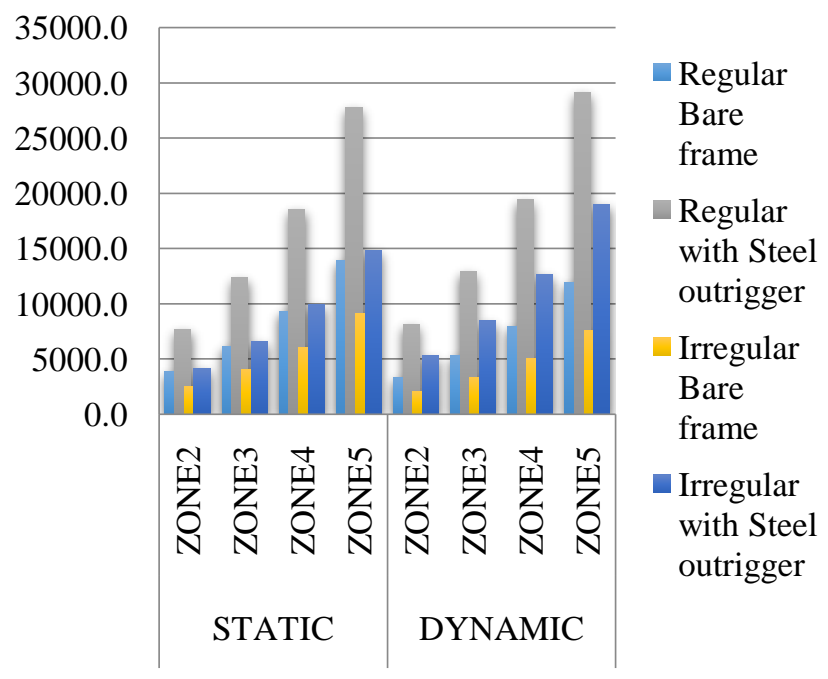

Chart -3: Base Shear in KN for different zones
The above graph shows the graph of base shear values for the regular and irregular buildings having outriggers with shear wall at the center in different zones from static and dynamic analysis. From the graph it is observed that the base shear of structure with steel outrigger and shear wall core gives higher value and Irregular bare frame gives lowest value. The percentage of increase in the values found to be $59.18 \%$ and $60.21 \%$ for regular and irregular buildings with steel outriggers respectively.

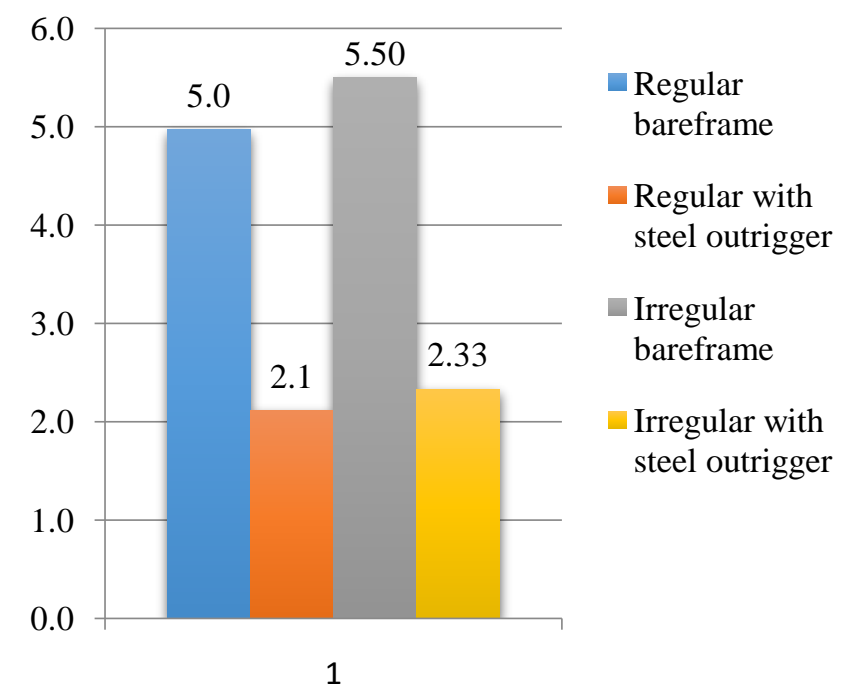

Chart-4: Time period for regular and irregular models

The above graph shows the graph of fundamental time period for regular and irregular building with and without steel outrigger. From graph it is observed that regular structure having shear wall core and steel outrigger gives lowest time period.

\section{CONCLUSION}

The present study is to compare the behavior of regular and irregular buildings with and without outriggers subjected to lateral loads. The significant parameters considered for the study are displacement, drift, base shear and time period. To analyze the seismic behavior of structure, models are subjected to seismic load as per IS 1893:2002 for zone zone2, zone3, zone4 and zone5. Similarly the structure were subjected to wind load as per IS 800 Part III for different wind speeds $33 \mathrm{~m} / \mathrm{s}, 39 \mathrm{~m} / \mathrm{s}, 47 \mathrm{~m} / \mathrm{s}$ and $55 \mathrm{~m} / \mathrm{s}$. Following conclusions are made for different cases considered in the regular and irregular buildings.

1. Displacement and drift for irregular building is greater than the regular building since, the stiffness of irregular building is less.

2. Base shear of regular building is greater than the irregular building, which indicates regular building is stiffer than irregular building.

3. Introduction of shear wall core in both regular and irregular building will increase the effective strength of the building.

4. Providing the outrigger along with shear wall core increases the strength as well as stiffness of the building 
5. For both wind and earthquake loading the most efficient structure is the structure having steel outrigger along with shear wall core.

6. By providing the outriggers at different levels, the reduction in inter storey drift can be achieved.

7. The least value of fundamental time period is given by structure having steel outrigger with shear wall of $2.1 \mathrm{sec}$ for regular building but for irregular building the period is about $2.3 \mathrm{sec}$.

\section{FUTURE SCOPE OF STUDY}

1. The varied outrigger depth can be adopted for comparative study.

2. Different type of irregularity can be considered for the seismic analysis.

3. Non- linear analysis on the outrigger structures can be performed.

4. Different type of steel bracings can be provided as outrigger and belt-truss.

\section{REFERENCES}

[1] Srinivas Suresh Kogilgeri and Beryl Shanthapriya, study on "Behavior of Outrigger system on high rise steel structure by varying outrigger depth". International Journal of Research in Engineering and Technology (IJRET), eISSN: 2319-1163, pISSN: 23217308, Volume: 04, Issue: 07, July 2015

[2] Abdul Karim Mulla and Srinivas B.N, study on "Outrigger system in Tall RC structure with steel bracing". International Journal of Research in Engineering and Technology (IJRET), ISSN: 22780181, Volume: 04, Issue: 07, July 2015

[3] Shivacharan. K, Chandrakala. S, Narayana G and Karthik. N. M, on "Analysis of outrigger systems for tall vertical irregular structures subjected to lateral loads". International Journal of Research in Engineering and Technology (IJRET), eISSN: 23191163, pISSN: 2321-7308, Volume: 04, Issue: 05, May 2015.

[4] Shruti Badami and M. R. Suresh, on "Study on behavior of structural systems for tall buildings subjected to lateral loads", International Journal of Research in Engineering and Technology (IJRET), ISSN: 2278-0181, Volume: 03, Issue: 07, July 2014.

[5] M. R. Jahanshahi and R. Rahgozar, on "Optimum location of outrigger belt truss in Tall buildings based on Maximization of belt truss strain energy". International Journal of Engineering, Volume: 26, No. 7, July 2013.

[6] P. M. B. Raj Kiran Nanduri, B. Suresh and MD. Ihtesham Hussain, on "Optimum position of Outrigger system for High rise Reinforced concrete buildings under wind and earthquake loadings". American Journal of Engineering Research (AJER), e-ISSN: 2320-0847, P-ISSN: 2320-0936, Volume- 02, Issue-08, pp-76-89

[7] Kiran Kamath, N. Divya and Asha. U. Rao, on "A study on static and dynamic behavior of Outrigger structural system for Tall buildings". Bonfring
International Journal of Industrial Engineering and Management science, Vol. 2, No. 4, December 2012.

[8] Prateek N. Biradar, Mallikarjun S. Bhandiwad, on "A performance based study on static and dynamic behavior of outrigger structural system for tall buildings", International Research Journal of Engineering and Technology (IRJET), e-ISSN: 23950056, p-ISSN: 2395-0072, Volume:02, Issue:05, August- 2015

[9] Sahana Ponnamma T. D, Santhosh D and R. Prabhakara, on "Comparitive study of pushover analysis of conventional slab system with outrigger and flat slab system with outrigger", International Journal of Innovative Research in Science, Engineering and Technology, Volume: 04, Issue: 08, August 2015

[10] S. Fawzia and T. Fatima, on "Deflection control in composite building by using belt truss and outigger systems", International Journal of Civil, Environmental, Structural, Construction and Architectural Engineering, Volume:04, No.12, 2010

[11] IS 1893 (Part-1)- 2002, "criteria for earthquake resistant design of structures"

[12] IS 875 (Part-3)- 1987, "criteria for wind resistant design of structures"

[13] IS 456-2000, "Plain and Reinforced concrete"

\section{BIOGRAPHIES}

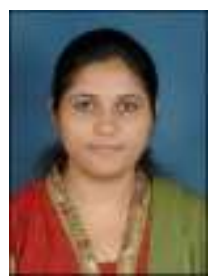

Mrs. SPOORTHI D C, pursuing MTech in Nagarjuna college of Engineering, Bangalore. Completed B.E.(Civil) in JNN college of Engineering, Shimoga.

Mr. Sridhar R, Sr. Assoc Professor, Department of Civil Engineering, Nagarjuna College of Engineering and Technology 